\title{
Genome-wide analysis of intracellular pH reveals quantitative control of cell division rate by $\mathrm{pH}_{\mathrm{c}}$ in Saccharomyces cerevisiae
}

Rick Orij ${ }^{1}$, Malene L Urbanus ${ }^{2}$, Franco J Vizeacoumar ${ }^{2}$, Guri Giaever ${ }^{3}$, Charles Boone ${ }^{2}$, Corey Nislow ${ }^{2}$, Stanley Brul ${ }^{1}$ and Gertien J Smits ${ }^{1 *}$

\begin{abstract}
Background: Because protonation affects the properties of almost all molecules in cells, cytosolic $\mathrm{pH}\left(\mathrm{pH}_{\mathrm{c}}\right)$ is usually assumed to be constant. In the model organism yeast, however, $\mathrm{pH}_{\mathrm{c}}$ changes in response to the presence of nutrients and varies during growth. Since small changes in $\mathrm{pH}_{c}$ can lead to major changes in metabolism, signal transduction, and phenotype, we decided to analyze $\mathrm{pH}_{c}$ control.

Results: Introducing a pH-sensitive reporter protein into the yeast deletion collection allowed quantitative genome-wide analysis of $\mathrm{pH}_{c}$ in live, growing yeast cultures. $\mathrm{pH}_{c}$ is robust towards gene deletion; no single gene mutation led to $\mathrm{p} \mathrm{H}_{\mathrm{c}}$ of more than 0.3 units lower than that of wild type. Correct $\mathrm{pH}_{c}$ control required not only vacuolar proton pumps, but also strongly relied on mitochondrial function. Additionally, we identified a striking relationship between $\mathrm{pH}_{c}$ and growth rate. Careful dissection of cause and consequence revealed that $\mathrm{pH}_{c}$ quantitatively controls growth rate. Detailed analysis of the genetic basis of this control revealed that the adequate signaling of $\mathrm{pH}_{c}$ depended on inositol polyphosphates, a set of relatively unknown signaling molecules with exquisitely $\mathrm{pH}$ sensitive properties.
\end{abstract}

Conclusions: While $\mathrm{pH}_{\mathrm{c}}$ is a very dynamic parameter in the normal life of yeast, genetically it is a tightly controlled cellular parameter. The coupling of $\mathrm{pH}_{c}$ to growth rate is even more robust to genetic alteration. Changes in $\mathrm{pH}_{c}$ control cell division rate in yeast, possibly as a signal. Such a signaling role of $\mathrm{pH}_{c}$ is probable, and may be central in development and tumorigenesis.

\section{Background}

Cytosolic $\mathrm{pH}\left(\mathrm{pH}_{\mathrm{c}}\right)$ determines the relative protonation state of all weak acid compounds of the cytosol and affects many, if not all, processes in the cell. It is known to affect redox equilibria [1], metabolic rates and energy storing or generating gradients $[2,3]$, protein interactions [4-7], as well as signal transduction [8-10], and it is an important thermodynamic constraint on metabolic reactions [11]. Furthermore, $\mathrm{pH}_{\mathrm{c}}$ homeostasis is intricately connected with that of other cations, with membrane potentials, and therefore with cellular energy homeostasis $[12,13]$.

\footnotetext{
* Correspondence: G.J.Smits@uva.nl

${ }^{1}$ Molecular Biology and Microbial Food Safety, Swammerdam Institute for Life Sciences, University of Amsterdam, Science Park 904, 1098 XH Amsterdam, the Netherlands

Full list of author information is available at the end of the article
}

Only relatively recently, with the development of green fluorescent protein (GFP)-based $\mathrm{pH}$ sensors, has it become possible to study $\mathrm{pH}$ in live, unperturbed cells, in an organelle specific fashion [14-18]. The use of this technology is generating increased insight into intracellular $\mathrm{pH}\left(\mathrm{pH}_{\mathrm{i}}\right)$ control, such as the interaction between plasma membrane and vacuolar proton transport $[16,19]$, and nutrient signaling and $\mathrm{pH}_{\mathrm{i}}$ control [10]. That $\mathrm{pH}_{\mathrm{c}}$ itself directly controls signal transduction and cellular transcriptional responses to environmental conditions was shown recently. A decrease of $\mathrm{pH}_{\mathrm{c}}$ from 7 to 6.8, induced by carbon source depletion, abolishes the interaction of the transcription factor Opi1p with phosphatidic acid through direct protonation of the phosphate headgroup of this membrane phospholipid [7]. Considering the known and emerging importance of this parameter, it is remarkable how little is understood of the genetic basis 
of its control. We decided to carefully study $\mathrm{pH}_{\mathrm{c}}$ in growing cultures of the yeast deletion collection [20], to determine the genes that are involved in $\mathrm{pH}_{\mathrm{c}}$ control during normal, fermentative growth on glucose. This revealed that $\mathrm{pH}_{\mathrm{c}}$ is controlled by the interplay of cation pumps and the mitochondria, even in fermenting cultures. Additionally, we determined that $\mathrm{pH}_{\mathrm{c}}$ quantitatively controls yeast cell division rate. Remarkably, deletion of 19 genes could abolish this control, suggesting that $\mathrm{pH}_{\mathrm{c}}$ functions as a true signal, transmitting information about external conditions to control cellular decisions.

\section{Results}

\section{$\mathrm{pH}_{\mathrm{c}}$ is dynamic during growth}

Cytosolic $\mathrm{pH}$ of yeast cultures is not a static but a highly dynamic parameter. Re-addition of glucose to starved cells leads to a rapid acidification of the cytosol in approximately 30 seconds followed by an alkalinization to neutral $\mathrm{pH}$ before growth recommences $[18,21,22]$. This rapid acidification, which is believed to be the cause of initiation of glycolysis $[10,23]$, is followed by an alkalinization as a result of the activation of the plasma membrane $\mathrm{H}^{+}$-ATPase Pmalp [24,25].

We assessed $\mathrm{pH}_{\mathrm{c}}$ in growing yeast cultures under batch conditions to reveal that $\mathrm{pH}_{\mathrm{c}}$ is not constant during growth. $\mathrm{pH}_{\mathrm{c}}$ was neutral in the beginning of the exponential growth phase, and then gradually dropped approximately $0.3 \mathrm{pH}$ units in mid- to late exponential phase, before glucose was depleted. Upon glucose depletion $\mathrm{pH}_{\mathrm{c}}$ decreased to 5.5 (Figure 1a). We determined that the gradual reduction of $\mathrm{pH}_{\mathrm{c}}$ from 7 to 6.7 during growth of the culture was a response to changes in the cellular environment, rather than a property of the cultured cells themselves: we took cell and culture supernatant samples from the beginning of the growth phase (where $\mathrm{pH}_{\mathrm{c}}$ was 7.0 and the specific growth rate $0.48 \mathrm{~h}^{-1}$ ) and at the end of the growth phase, just prior to glucose depletion, when the $\mathrm{pH}_{\mathrm{c}}$ and growth rate were decreased. Inoculation of old cells in fresh medium rapidly (within a minute) restored $\mathrm{pH}_{\mathrm{c}}$ to 7.0, while the addition of old, depleted culture supernatant to fresh cells set $\mathrm{pH}_{\mathrm{c}}$ to 6.85 (Figure 1b). Nutrient depletion at the end of the growth phase was not the cause of this intracellular acidification, as supplementation of the conditioned medium with all fresh nutrients did not restore $\mathrm{pH}_{\mathrm{c}}$. Rather, it appeared that the yeast cells had conditioned the medium such that it now induced a low $\mathrm{pH}_{\mathrm{c}}$. We determined the concentrations of secreted ethanol and weak organic acids such as succinate, acetate, and pyruvate in the conditioned medium. Addition of the same quantity of these compounds to fresh medium did not lead to a decreased $\mathrm{pH}_{\mathrm{c}}$ (our unpublished data). In contrast, aeration of the conditioned medium relieved its $\mathrm{pH}_{\mathrm{c}}$ lowering effect, strongly suggesting that the main component of the acidifying activity was dissolved $\mathrm{CO}_{2}$, acting as a weak acid to acidify the cytoplasm (Figure 1c). Similar acidification occurred even in well shaken Erlenmeyer flask cultures, usually considered properly aerated.

\section{Identification of $\mathrm{pH}_{\mathrm{c}}$ mutants}

To understand the genetic basis of the control of this central cellular parameter, we performed a genome-wide analysis of $\mathrm{pH}_{\mathrm{c}}$ in growing cultures of the deletion mutant array (DMA) [20]. The pH-sensitive GFP ratiometric pHluorin $[17,18]$ was introduced in 4,308 haploid mutants of the DMA using synthetic genetic array (SGA) methodology [26]. All mutants were screened in duplicate during mid-exponential phase in microplates at $30^{\circ} \mathrm{C}$ in medium buffered at $\mathrm{pH}$ 5.0. Candidates were selected based on their deviation from the parent $\mathrm{pH}_{\mathrm{c}}$ of $7.08 \pm$ 0.05 (measured in 2,088 biological replicates; Figure 2a). These candidates, along with 432 slow growing mutants that were separately arrayed because they are usually lost during the growth and selection steps of the SGA procedure, were analyzed in six additional biological replicates to obtain statistically valid $(P<0.01)$ hits (Additional File 1, Table S1). Out of a total of 4,740 mutants screened, we identified 177 mutants with significantly high (104) or low (73) $\mathrm{pH}_{\mathrm{c}}$. All significant mutants were microscopically evaluated for aberrant GFP distribution. No indications of aggregation or cell lysis were found. The $\mathrm{pH}_{\mathrm{c}}$ of these mutant strains was never more than $0.3 \mathrm{pH}$ units below or $0.5 \mathrm{pH}$ units above parent $\mathrm{pH}_{\mathrm{c}}$. The re-screening of the candidate hits allowed for an accurate false negative estimation (Figure $2 \mathrm{~b}$ ): we applied the criteria for the selection of candidates from the original duplicate screening to the separately arrayed slow grower array, and used this to determine the false negative rate in the initial screening of the 4,308 DMA mutants. This revealed that we successfully identified $86 \%$ of the genes with low $\mathrm{pH}_{\mathrm{c}}$ and $95 \%$ of the genes with high $\mathrm{pH}_{\mathrm{c}}$.

We failed to identify several mutants that we expected to have an altered pHc. We separately tested several of these, among which were trk1, trk2, nha1, nhx1. In our analysis, cells growing on defined media with glucose available, these mutants did not have a significantly deviating $\mathrm{pH}_{\mathrm{c}}$. We have shown before [7] that, in such conditions, a PMA1 hypomorph $y g l 007 c$ and a trk1 deletion strain do not have a $\mathrm{pH}_{\mathrm{c}}$ phenotype, and that such a phenotype only becomes apparent when the cells are challenged with low external $\mathrm{pH}$. At an external $\mathrm{pH}$ $\left(\mathrm{pH}_{\mathrm{ex}}\right)$ of 3.0, trk1, trk2, nha1 and $n h x 1$ had $\mathrm{pH}_{\mathrm{c}}$ values of $6.93 \pm 0.02,7.02 \pm 0.06,6.99 \pm 0.01$ and $7.08 \pm 0.10$, respectively (with average $\mathrm{Z}$-values of $-2.77,-0.99,-1.32$ and 0.02), which indicates a significant $\mathrm{pH}_{\mathrm{c}}$ deviation for trk1 only. This suggests that, although the gene products 

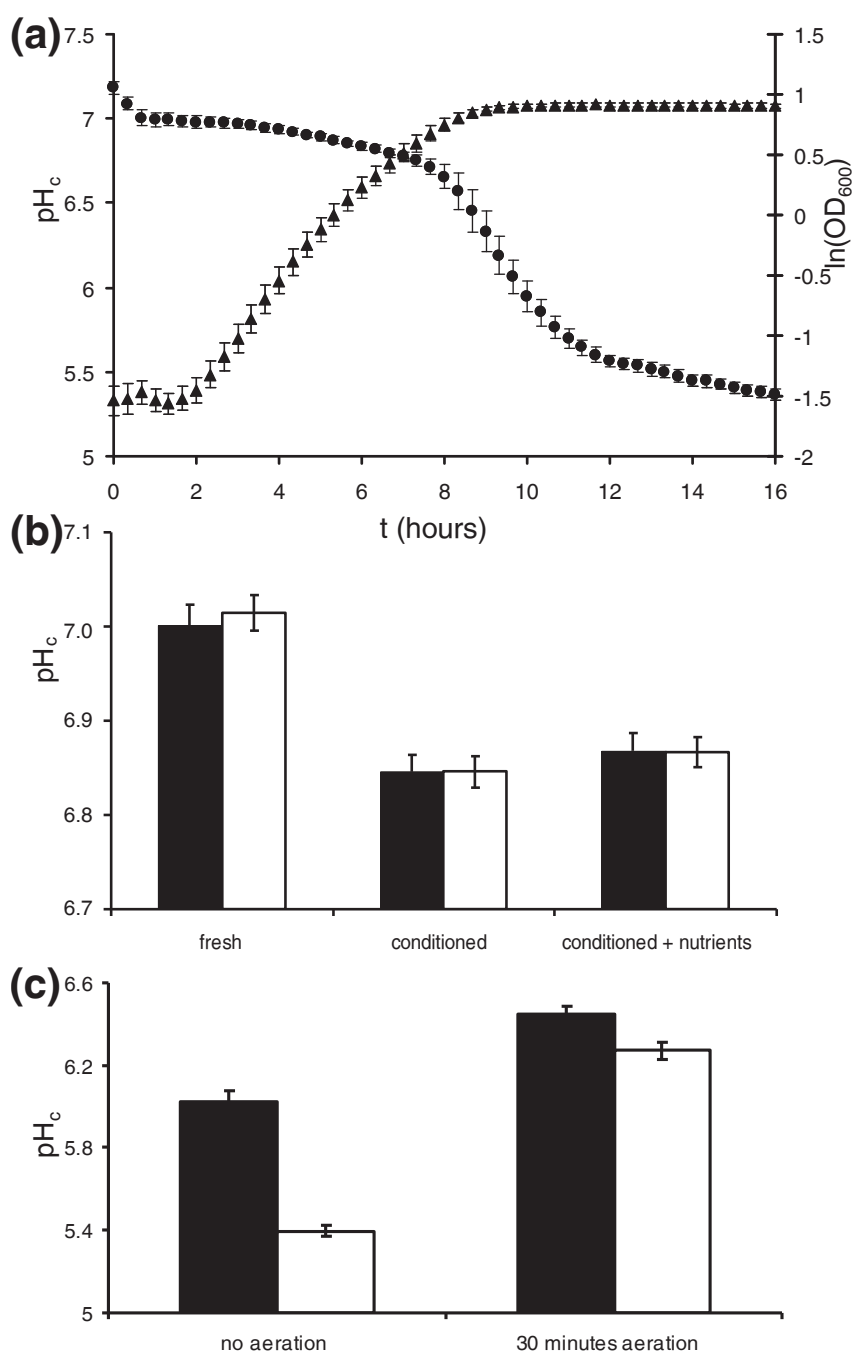

Figure $1 \mathbf{p H}_{\mathbf{c}}$ dynamics during growth. (a) Growth (filled triangles) and $\mathrm{pH}_{\mathrm{c}}$ (filled circles) were monitored during growth on glucose in microplates. Data points represent the average of 24 biological replicates, error bars represent standard deviations. (b) Medium exchange experiments show that the $\mathrm{pH}_{c}$ decrease during the growth phase is determined not by the state of the cell, but the environmental conditions generated in the culture medium. Early and late log phase cells were harvested and resuspended in fresh medium, late log medium, and late log medium supplemented with all nutrients. (c) $\mathrm{CO}_{2}$ causes $\mathrm{pH}_{c}$ acidification. Strains were grown for 10 hours in either aerobically (closed bars) or anaerobically (open bars). After 10 hours the $\mathrm{pH}_{c}$ of both strains was determined. Cultures were subsequently aerated for 30 minutes by bubbling air through the culture followed by $\mathrm{pH}_{c}$ determination.

have well defined functions in cation homeostasis, deletion of these genes when sufficient cellular energy can be generated does not cause a $\mathrm{pH}_{\mathrm{c}}$ decrease.

Profiling of mutants with aberrant $\mathrm{pH}_{\mathrm{c}}$ under additional stress conditions reveals involvement of vacuole and mitochondria in $\mathrm{pH}_{\mathrm{c}}$ control

The $\mathrm{pH}_{\mathrm{c}}$ mutants were analyzed for functional enrichment based on their gene ontology terms (Figure 2c). As expected, functional groups related to proton and cation homeostasis were strongly enriched, including vacuolar proton pumping [16]. The genes we identified in these functional groups are required to maintain $\mathrm{pH}_{\mathrm{c}}$, and we expected, therefore, that these and our other $\mathrm{pH}_{\mathrm{c}}$ mutants would have difficulty to control $\mathrm{pH}_{\mathrm{c}}$ during growth in media conditions that were close to the lower and upper tolerance external $\mathrm{pH}\left(\mathrm{pH}_{\mathrm{ex}}\right)$ limits for yeast growth. Most Saccharomyces strains will grow at $\mathrm{pH}_{\mathrm{ex}}$ values of 2.5 to 8.5 , and the kinetics of growth and fermentation are not affected between $\mathrm{pH} 3.5$ and 6.0 because of the tight control of intracellular $\mathrm{pH}$ [27]. We decided upon media $\mathrm{pH}$ values of 3.0 and 7.5 , which induce considerable stress, yet allow for significant cell growth and pHluorin expression. Wild-type $\mathrm{pH}_{\mathrm{c}}$ is unaffected by cultivation at a $\mathrm{pH}_{\mathrm{ex}}$ of 3.0 compared to a $\mathrm{pH}_{\mathrm{ex}}$ of 5.0, and slightly increased during cultivation at a $\mathrm{pH}_{\mathrm{ex}}$ 

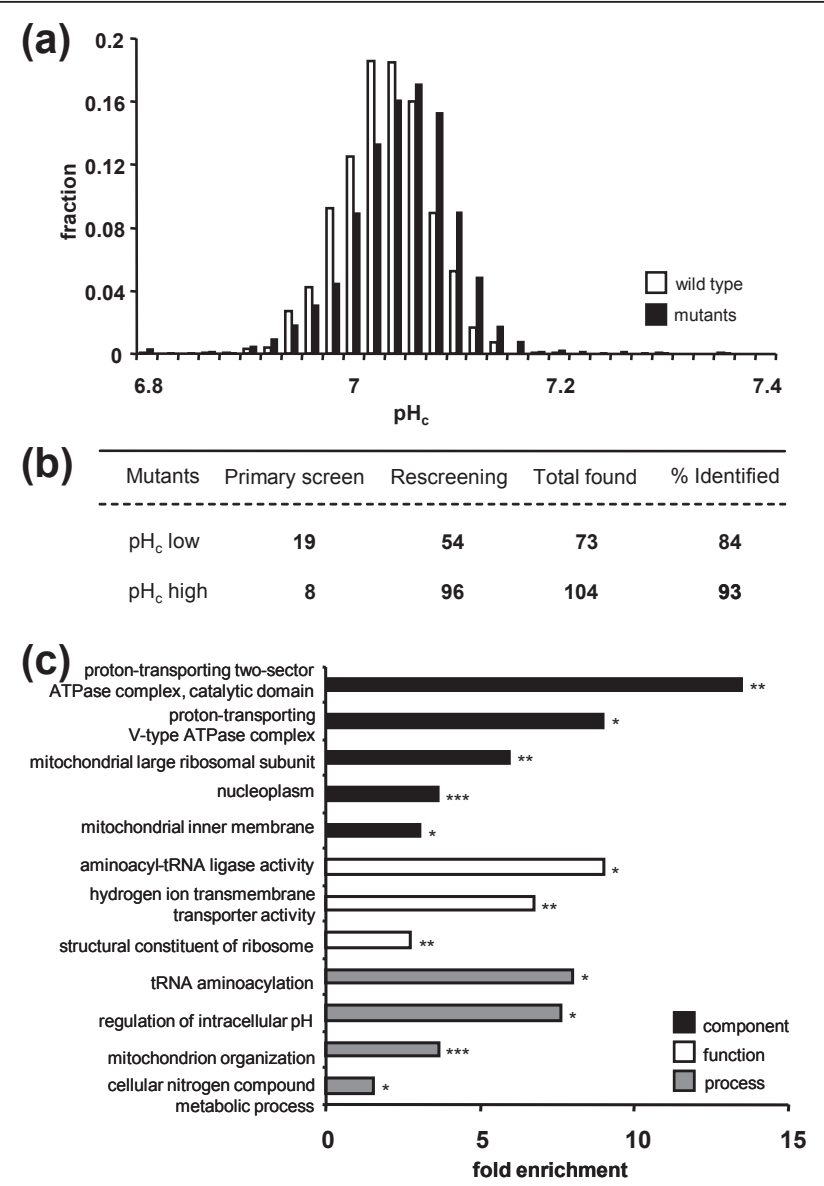

Figure 2 Genome-wide analysis of $\mathbf{p H}_{\mathbf{c}}$ in growing yeast mutant cultures. (a) Distribution of average $\mathrm{pH}_{\mathrm{c}}$ values of 1,068 wild-type and 4,208 deletion mutant strains in two biological replicate screenings of exponentially growing cultures. (b) $\mathrm{pH}_{\mathrm{c}}$ mutants identified in primary and secondary screens. Significantly deviating mutants $(P$-value $<0.01)$ were identified after six biological replicate determinations of $\mathrm{pH}_{c}$ in cultures 4 hours after initiation of growth on glucose. (c) Hypergeometric enrichment of Gene Ontologies in $\mathrm{pH}_{c}$ mutants. Fold enrichment is defined as the number of mutants in a given ontology in the $\mathrm{pH}_{c}$ mutant dataset relative to the number of mutants in that ontology in the screened background dataset (4,740 mutants). ${ }^{*} P$-value $<0.05,{ }^{*} P$-value $<0.01,{ }^{* *} P$-value $<0.001$.

of 7.5 (Additional file 1). We identified 20 mutants that had a low $\mathrm{pH}_{\mathrm{c}}$ at all $\mathrm{pH}_{\mathrm{ex}}$ conditions, and 19 that had a consistently high $\mathrm{pH}_{\mathrm{c}}$ (Figure 3a; Additional file 1), and found that these 39 were enriched for global growthrelated functions such as RNA polymerase II-mediated transcription and mitochondrial translation. Remarkably, we did not find a clear indication that loss of proton homeostasis mechanisms led to a $\mathrm{pH}_{\mathrm{c}}$ phenotype that became much more sensitive to $\mathrm{pH}_{\mathrm{ex}}$ changes; if we define a $\mathrm{pH}$-fragile mutant as one that has a high $\mathrm{pH}_{\mathrm{c}}$ at a $\mathrm{pH}_{\mathrm{ex}}$ of 7.5, but a low $\mathrm{pH}_{\mathrm{c}}$ at a $\mathrm{pH}_{\mathrm{ex}}$ of 3.0, we could identify only four mutants (rpl31a $\Delta$, gpm $2 \Delta$, pet $111 \Delta$, and $\operatorname{erg} 28 \Delta$ ) that had lost the capacity to maintain $\mathrm{pH}_{\mathrm{c}}$ with respect to $\mathrm{pH}_{\mathrm{ex}}$, which is less than could be expected by coincidence.

Mitochondrial proton pumping functions, as well as functions related to mitochondrial biogenesis and inheritance, were strongly enriched, despite the fact that respiration is not required for energy generation during fermentative growth on glucose. To see if this mitochondrial role in $\mathrm{pH}_{\mathrm{c}}$ homeostasis is related to the role of the mitochondria in energy generation, we assessed the $\mathrm{pH}_{\mathrm{c}}$ of all $\mathrm{pH}_{\mathrm{c}}$ mutants during respiratory growth in glyceroland ethanol-containing medium (Figure $3 \mathrm{~b}$ ). The average parent $\mathrm{pH}_{\mathrm{c}}$ on respiratory medium was reduced by 0.27 $\mathrm{pH}$ units, and similarly almost all mutants tested had a lower $\mathrm{pH}_{\mathrm{c}}$ on respiratory medium. However, only 13 of the 73 strains with a significantly low $\mathrm{pH}_{\mathrm{c}}$ on glucose were also significantly low during respiratory growth, when compared to wild type. Eleven of these (msf $1 \Delta$,

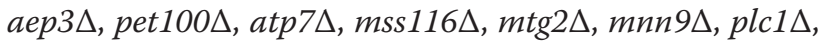
dep $1 \Delta$, rpl21a $\Delta$, and $\operatorname{snf} 2 \Delta$ ) had extremely low growth rates on glycerol/ethanol medium, and were indeed previously shown to have severely reduced growth on respiratory media or to be respiratory growth deficient

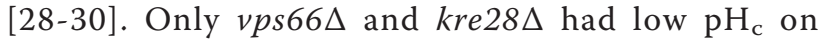



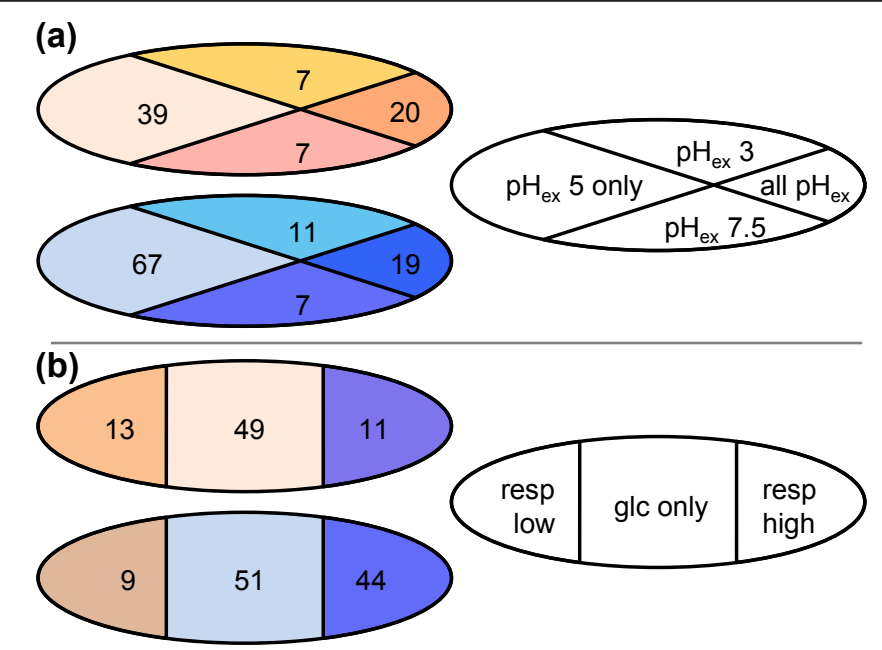

Figure 3 Profiling of mutants with aberrant $\mathbf{p H}_{\mathbf{c}}$. $(\mathbf{a}, \mathbf{b})$ Venn diagrams of mutants with significantly low $\mathrm{pH}_{c}$ (top) or significantly high $\mathrm{pH}_{c}$ (bottom) during growth at the normal $\mathrm{pH}_{\mathrm{ex}}$ of 5.0 and during growth at extreme $\mathrm{pH}_{\mathrm{ex}}$ values of 3.0 and 7.5 (wild-type $\mathrm{pH}_{\mathrm{c}}$ of $7.08 \pm 0.03$ and $7.20 \pm 0.15$, respectively) (a), or with significantly low $\mathrm{pH}_{c}$ (top) or significantly high $\mathrm{pH}_{\mathrm{c}}$ (bottom) during growth in medium with $2 \%$ glucose, upon growth on $2 \%$ ethanol and $2 \%$ glycerol as respiratory carbon source (wild-type $\mathrm{pH}_{c}$ of $6.93 \pm 0.06$ ) (b).

respiratory and fermentative carbon sources but were able to grow relatively normally on respiratory media compared to fermentative conditions. The other 60 strains with low $\mathrm{pH}_{\mathrm{c}}$ during fermentative growth had normal or even high $\mathrm{pH}_{\mathrm{c}}$ during respiratory growth. This apparent rescue of most low $\mathrm{pH}_{\mathrm{c}}$ phenotypes shows that $\mathrm{pH}_{\mathrm{c}}$ regulation in fermenting cells is very different from that in respiring cells, as suggested before [18]. Together, our data establish the major importance of the vacuole and mitochondria in $\mathrm{pH}$ control, and reveal these organelles as central controllers of cytosolic ion concentrations $[16,19,31,32]$.

\section{$\mathrm{pH}_{\mathrm{c}}$ controls growth rate}

Because many growth-related functions were enriched in the deviant $\mathrm{pH}_{\mathrm{c}}$ mutants, we decided to directly analyze the relationship of $\mathrm{pH}_{\mathrm{c}}$ and growth rate in detail. We assessed the relation between growth rate and $\mathrm{pH}_{\mathrm{c}}$ in the parent strain and found a strong correlation between $\mathrm{pH}_{\mathrm{c}}$ and growth rate $(\mu)$ over all time points of the experiment after the cells had resumed growth, which could be recapitulated as a linear relation between $\log (\mu)$ and $\mathrm{pH}_{\mathrm{c}}$ $\left(\mathrm{R}^{2}=0.99\right.$ over all the time points between $\mathrm{t}=2 \mathrm{~h}$ and $\mathrm{t}=16 \mathrm{~h}$ from 24 biological replicates) (Figure 4a). Even after glucose depletion (around 8 hours cultivation time in this experiment), when the growth rate is gradually reduced to 0 and the $\mathrm{pH}$ is reduced to approximately 5.5 , the relationship of $\mathrm{pH}_{\mathrm{c}}$ and growth rate is maintained. Only the time points before $\mathrm{t}=2 \mathrm{~h}$ (grey dots in Figure $4 \mathrm{a}$ ) do not fit the relationship but cluster around $\mathrm{pH} 7,0$, because $\mathrm{pH}_{\mathrm{c}}$ already increased upon re-inoculation in fresh medium before growth was observable. The strong correlation of two such central parameters of cellular functioning raises the question if $\mathrm{pH}_{\mathrm{c}}$ might determine growth rate, growth rate $\mathrm{pH}_{\mathrm{c}}$, or whether there is a process that controls both. To establish causality we first note that effects on $\mathrm{pH}_{\mathrm{c}}$ are rapid, and precede alterations of growth rate. First, at the beginning of growth, $\mathrm{pH}_{\mathrm{c}}$ already increases to 7.0 before growth of the culture starts (Figures 1 and $4 a$ ). Second, we established that the gradual reduction of $\mathrm{pH}_{\mathrm{c}}$ from 7 to 6.7 during growth of the culture is rapidly induced by the cellular environment at those times, rather than a property of the cells themselves (Figure 1b). The rate at which the $\mathrm{pH}_{\mathrm{c}}$ dropped when cells were exposed to this conditioned medium suggests that the $\mathrm{pH}_{\mathrm{c}}$ drop precedes the drop in growth rate. The hypothesis that growth rate controls $\mathrm{pH}_{\mathrm{c}}$ is also contradicted by the observation that most slow growing mutants (276 out of 432 tested) had a normal $\mathrm{pH}_{\mathrm{c}}$ (Additional file 2). Together, these data render it highly unlikely that growth rate controls $\mathrm{pH}_{\mathrm{c}}$.

To positively demonstrate that $\mathrm{pH}_{\mathrm{c}}$ dictates growth rate, we postulated that it should then be possible to titrate $\mathrm{pH}_{\mathrm{c}}$, which should allow us to set the growth rate to the values predicted by the quantitative relationship previously determined (Figure 4a). In wild-type strains, the plasma membrane ATPase ensures $\mathrm{pH}_{\mathrm{c}}$ control in different $\mathrm{pH}_{\mathrm{ex}}$ conditions [18,33], and titration of $\mathrm{pH}_{\mathrm{ex}}$ leads to only minute changes in $\mathrm{pH}_{\mathrm{c}}$ (Figure S1 in Additional file 3). However, in a mutant with a hypomorphic allele of PMA1 (pma1-007), with approximately 50\% reduced plasma membrane ATPase levels and activity $[7,34]$, acidification of the culture medium with $\mathrm{HCl}$ from $\mathrm{pH} 5.0$ to $\mathrm{pH} 2.0$ resulted in a $\mathrm{pH}_{\mathrm{c}}$ decrease from 7.0 to 6.2 (Figure 4b), while nutrient abundance is not affected. Cultivation in these conditions revealed that growth was also progressively decreased (Figure 4c). Direct comparison of growth 

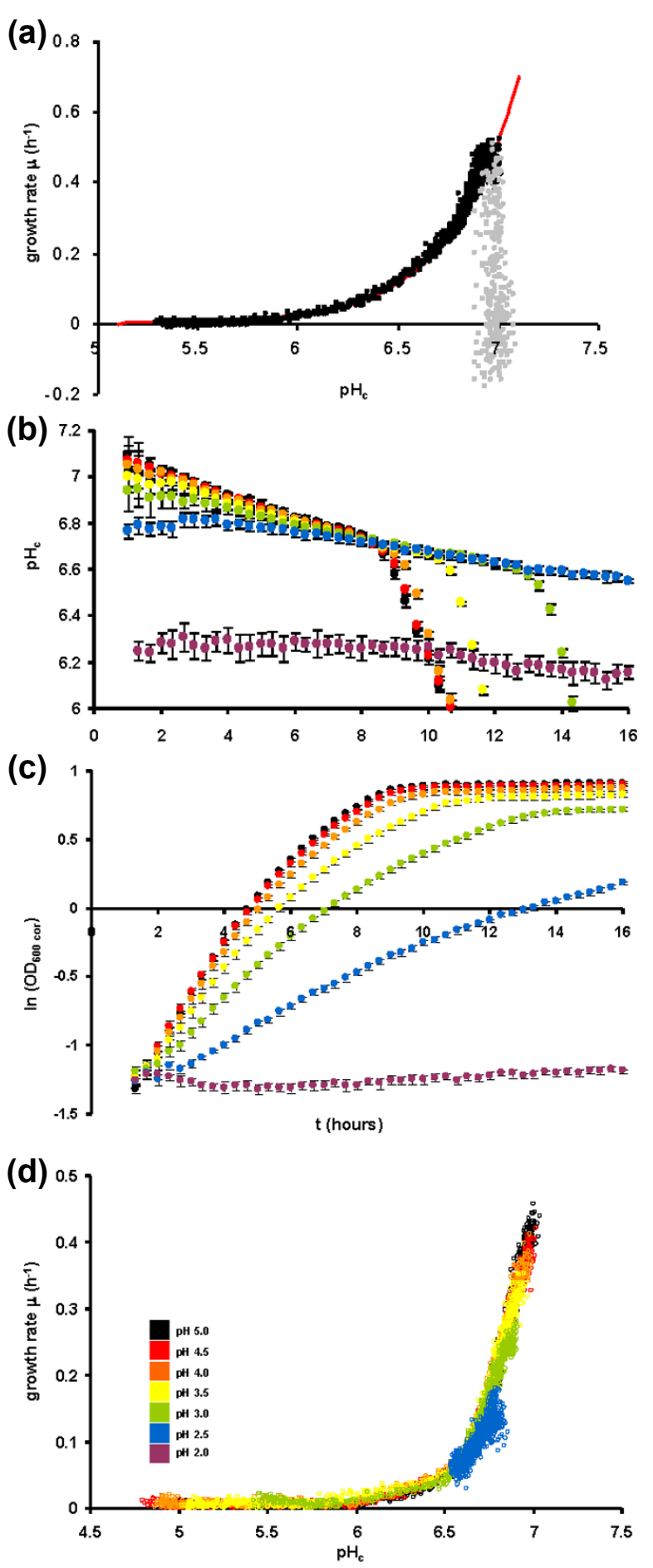

Figure 4 Cause and effect in the relationship between $\mathrm{pH}_{\mathbf{c}}$ and growth rate. (a) Wild-type $\mathrm{pH}_{c}$ plotted against growth rate $\mu$. Dots represent the time course data of 24 independent biological replicates of full 16 hour growth curves. The data were fit to an exponential dependence of $\mu$ on $\mathrm{pH}_{\mathrm{c}}$ (Additional file 1). Grey dots represent points from the first 1.5 hours after inoculation into fresh medium. (b-d) Titration of $\mathrm{pH}_{\mathrm{c}}$ sets growth rate. Strain pma1-007 was cultivated in unbuffered, $\mathrm{pH}_{\mathrm{ex}}$ controlled batch fermentors, and titrated to $\mathrm{pH}$ ex values indicated using strong acid $(\mathrm{HCl})$. Figures represent $\mathrm{pH}_{c}(\mathrm{~b})$, growth $(\mathrm{c})$, and $\mathrm{pH}_{\mathrm{c}}$ plotted against growth rate $\mu$ (d). Data points represent the average of 12 technical replicates, error bars represent standard deviations. 
rate and $\mathrm{pH}_{\mathrm{c}}$ revealed that the growth rate was decreased exactly to the extent expected from the lowering of $\mathrm{pH}_{\mathrm{c}}$ (Figure $4 \mathrm{~d}$ ), thus showing that $\mathrm{pH}_{\mathrm{c}}$ determines the growth rate.

\section{$\mathrm{pH}_{\mathrm{c}}$ appears to have a signaling role}

Now that we have determined that $\mathrm{pH}_{\mathrm{c}}$ controls growth rate, we could analyze the genes that are required for maintaining this relationship. Analysis of all $\mathrm{pH}_{\mathrm{c}}$ mutants with respect to this same $\mathrm{pH}_{\mathrm{c}}$-growth rate relationship revealed three distinct classes of mutants (Figure 5a; Figure S2 in Additional file 3; Additional file 4). Category I had a $\mathrm{pH}_{\mathrm{c}}$ that significantly deviated from wild type $\mathrm{pH}_{\mathrm{c}}$ during exponential growth, but the normal relationship between $\mathrm{pH}_{\mathrm{c}}$ and growth rate was maintained. Wild-type strains analyzed of course cluster with this category. The genes mutated in this case can be considered upstream of $\mathrm{pH}_{\mathrm{c}}$, and thus control $\mathrm{pH}_{\mathrm{c}}$. The effect they have on growth rate is through their effect on $\mathrm{pH}_{\mathrm{c}}$ only. This category contained the majority of the mutants identified in our screen (92 out of 173 mutant strains). Most of the cation and $\mathrm{pH}$ homeostasis-related genes identified in the screen fell into this category, as well as many involved in mitochondrial translation and oxidative phosphorylation (Figure 5b). Category II (62 out of 173 mutant strains) had a significantly low growth rate compared to the $\mathrm{pH}_{\mathrm{c}}$, which suggests that these mutations limit growth rate though mechanisms other than $\mathrm{pH}_{\mathrm{c}}$. Indeed, many of these mutants had a high $\mathrm{pH}_{\mathrm{c}}$ in our screen (45 out of 62 ), even while growth rate was reduced compared to wild-type. We selected a set of slow growing mutants with deletions in genes involved in ribosome biogenesis and central carbon metabolism that do not exhibit aberrant $\mathrm{pH}_{\mathrm{c}}$, and used the same analysis of growth rate/ $\mathrm{pH}_{\mathrm{c}}$ relationship, to show that these would fall into the same category (Figure S3 in Additional file 3). Indeed, very general functions are enriched in this cluster, such as polymerase II-mediated transcription, and ATP generating processes (Figure 5c). Any effect of such functions on $\mathrm{pH}_{\mathrm{c}}$ is likely indirect - for instance, because expression of $\mathrm{pH}$ regulatory genes is RNA polymerase II mediated $[35,36]$, or proton homeostatic processes depend on ATP $[2,3]$. Finally, mutants in category III had a low $\mathrm{pH}_{\mathrm{c}}$ and regularly also a low growth rate, but, more importantly, their growth rate was no longer as constricted by this low $\mathrm{pH}_{\mathrm{c}}$ as in the wild type. Only 19 of 173 mutants fall into this category (Table 1), suggesting a coupling that is robust to mutations in single genes. The fact that the deletion of single genes can lead to (partial or full) evasion of the control of $\mathrm{pH}_{\mathrm{c}}$ over growth rate shows that $\mathrm{pH}_{\mathrm{c}}$ is not somehow rate limiting for growth because of the complex integrated effect of protonation of many cellular components. This strongly suggests that $\mathrm{pH}_{\mathrm{c}}$ functions as a true signal that must be transduced. Although again the genes in this category were enriched for basic mitochondrial functions, we also found enrichment for genes involved in signal transduction and inositol pyrophosphate metabolism (Figure 5d). These highenergy metabolites are proposed to be involved in the sensing of a cell's energy status [37]. Interestingly, kcs1 and $p l c 1 \Delta$, involved in inositol pyrophosphate metabolism, both show growth that is no longer limited by $\mathrm{pH}_{\mathrm{c}}$ as it is in the wild type (Figure 5e). For $k c s 1 \Delta$, this entails a growth rate of $0.30 \mathrm{~h}^{-1}$ instead of the expected $0.18 \mathrm{~h}^{-1}$ at a $\mathrm{pH}_{\mathrm{c}}$ of 6.7, and the difference is most apparent at relatively normal $\mathrm{pH}_{\mathrm{c}}$ values. For $p l c 1 \Delta$ the phenotype is even more striking, with growth rate being more or less constant (although never very high) until $\mathrm{pH}_{\mathrm{c}}$ values of 5 , below which growth suddenly collapses. These two mutants are both among the mutants with the lowest $\mathrm{pH}_{\mathrm{c}}$ in the screen (Additional file 1). The $\mathrm{pH}$ dependence of the charge of the many phosphates on inositol poly- or pyrophosphates renders these metabolites exquisitely suitable for $\mathrm{pH}_{\mathrm{c}}$ sensing. Three other mutants in the inositol pyrophosphate synthesis pathway, vip1 $1 \Delta$ and ipk $1 \Delta$ (deletion of genes encoding enzymes responsible for pyrophosphorylation of inositol hexakisphosphate (InsP6) at the 1-P or 3-P position) and $d d p 1 \Delta$ (deletion of the gene encoding the phosphatase that removes the pyrophosphates) [38,39], did not affect $\mathrm{pH}_{\mathrm{c}}$ or $\mathrm{pH}_{\mathrm{c}}$ signaling to growth rate (Figure $\mathrm{S} 4$ in Additional file 3).

\section{Discussion}

\section{Complex control of a simple parameter}

It is becoming apparent that $\mathrm{pH}_{\mathrm{c}}$ is controlled not just by simply pumping protons out of the cytosol into the vacuole or across the plasma membrane. The $\mathrm{pH}$ of the various compartments is heavily influenced by that of others [16]. Vacuolar ATPases are not only important for maintenance of the low $\mathrm{pH}$ in the secretory pathway, but also for control of cytosolic $\mathrm{pH}$. This could be a buffering activity, a transient and rapid mode of removing protons from the cytosol, to be made permanent by true proton efflux. It should be noted, however, that a transient storage of protons in the secretory pathway or the vacuole conserves the energy in the cell as a membrane potential. Most of the components of the vacuolar ATPases have been identified based on the vma phenotype, which comprises the inability to grow at high extracellular $\mathrm{pH}$ and at high $\mathrm{Ca}^{2+}$ concentrations $[40,41]$. It is remarkable, therefore, that not all vma mutants have a $\mathrm{pH}_{\mathrm{c}}$ phenotype at a $\mathrm{pH}_{\mathrm{ex}}$ of 5.0, and of the ones that do, not all have a $\mathrm{pH}_{\mathrm{c}}$ phenotype at a $\mathrm{pH}_{\mathrm{ex}}$ of 7.5 (2 out of 7). Similarly, we found very little correlation between our screen for $\mathrm{pH}_{\mathrm{c}}$ and a recent screen for mutations leading to deviating vacuolar $\mathrm{pH}$, although conditions were different [42]. 


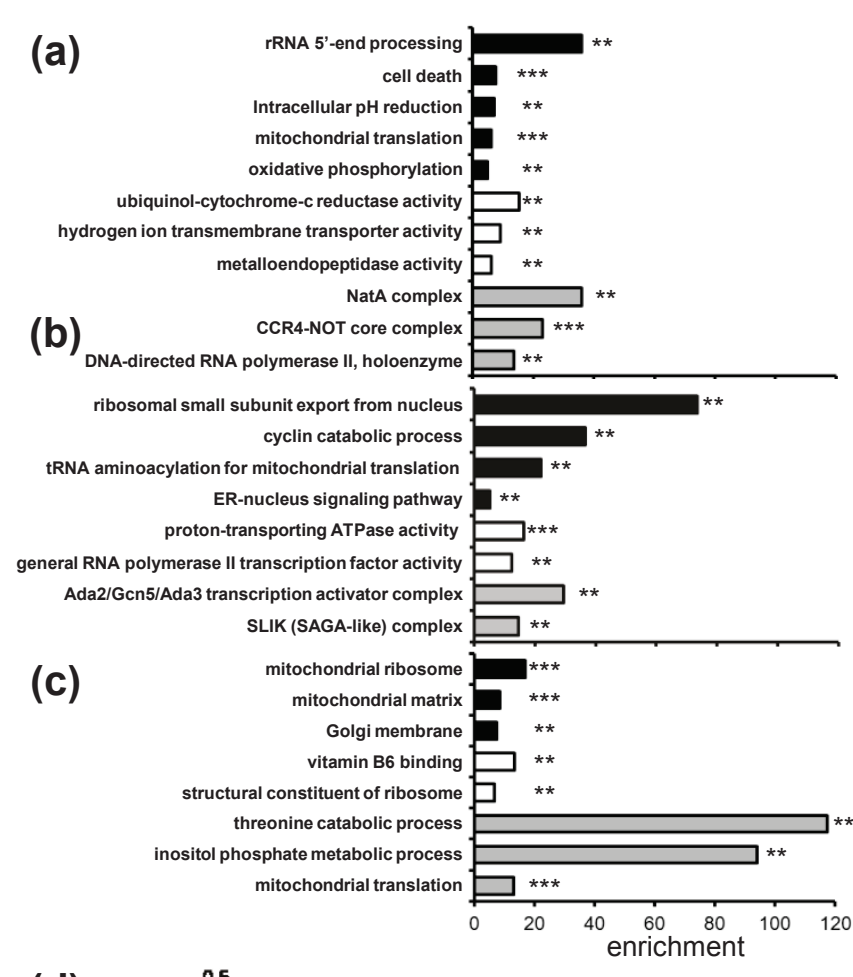

(d)

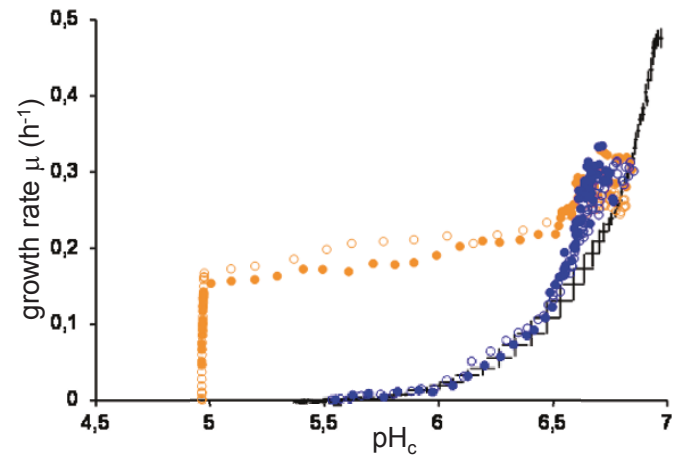

Figure 5 Mutant $\mathbf{p H}_{\mathbf{c}}$-growth rate relationship. (a-c) Gene ontology enrichment analysis of the wild-type (a), low growth rate (b), and high growth rate (c) cluster. (d) In $k c s i \Delta$ (blue symbols) and p/ci $\Delta$ (orange symbols) growth rate is no longer normally restricted by $\mathrm{pH}_{\mathrm{c}}$. Biological duplicates (open and closed symbols) are shown, compared to wild-type variance of 96 replicates indicated by average \pm standard deviation of both $\mathrm{pH}_{\mathrm{c}}$ and growth rate (black crosses).

This suggests that even if the mechanisms for $\mathrm{pH}_{\mathrm{c}}$ control share components with those for vacuolar $\mathrm{pH}$ control, the organelles control their $\mathrm{pH}$ independently.

While the role of vacuolar proton pumping in $\mathrm{pH}_{\mathrm{c}}$ homeostasis has been relatively well studied, the important role of the mitochondria is novel. In an analysis of mutations affecting the 'ionome' of yeast, a similar enrichment of both vacuolar and mitochondrial genes was observed [31], suggesting that the homeostasis of cations in general requires the proper function of both organelles. However, this analysis does not distinguish the organelle-specific ion concentrations. A role for mitochondria in $\mathrm{pH}_{\mathrm{c}}$ homeostasis is less surprising if one considers the fact that proton translocation over the mitochondrial inner membrane is the driving force for energy generation in mitochondria. However, in the glucose-rich conditions of our screen the mitochondrial respiratory chain is not required for energy generation in yeast. Still, we identified a large number of mutants in mitochondrial genes in which $\mathrm{pH}_{\mathrm{c}}$ was affected. The genes were classified as part of the proton translocating machinery and the mitochondrial respiratory chain, but also as involved in mitochondrial translation and biogenesis. The same mutations did not necessarily affect $\mathrm{pH}_{\mathrm{c}}$ in respiratory conditions, which suggests that the role of these genes in $\mathrm{pH}_{\mathrm{c}}$ homeostasis is indeed not linked to energy generation.

Clearly, the control of $\mathrm{pH}_{\mathrm{c}}$ in yeast, and in other eukaryotes $[32,43]$ is distributed over various organelles, as is 
Table 1 Mutations that reduce growth control by $\mathrm{pH}_{\mathrm{c}}$

\begin{tabular}{lllll}
\hline Category & Gene & ORF & Absolute $\mathbf{p H}_{\mathbf{c}}{ }^{\mathbf{a}}$ & GO process \\
\hline Inositol polyphosphates & PLC1 & YPL268W & $6.92(0.035)$ & Inositol phosphate biosynthetic process \\
Signal transduction & KCS1 & YDR017C & $6.76(0.047)$ & Inositol phosphate biosynthetic process \\
& LCB5 & YLR260W & $6.99(0.034)$ & Calcium-mediated signaling \\
Lipid synthesis & RHO5 & YNL180C & $7.02(0.025)$ & Rho protein signal transduction \\
Vesicular transport & CAX4 & YGR036C & $6.93(0.057)$ & Lipid biosynthetic process \\
& PDX3 & YBR035C & $6.99(0.025)$ & Fatty acid metabolic process \\
Mitochondria & RGP1 & YDR137W & $6.92(0.031)$ & Retrograde transport, endosome to Golgi \\
& CLC1 & YGR167W & $7.01(0.049)$ & Endocytosis \\
& RSM24 & YDR175C & $7.01(0.024)$ & Mitochondrial translation \\
& MRPL27 & YBR282W & $7.00(0.019)$ & Mitochondrial translation \\
Various & YBL038W & $6.97(0.028)$ & Mitochondrial translation \\
& MRPL16 & YBR268W & $6.98(0.032)$ & Mitochondrial translation \\
& MRPS5 & YBR251W & $7.00(0.027)$ & Mitochondrial translation \\
& MSS2 & YDL107W & $7.00(0.035)$ & Protein insertion \\
Unknown & YER086W & $6.98(0.035)$ & Isoleucine biosynthetic process \\
\hline
\end{tabular}

a Wild-type $\mathrm{pH}$ average is $7.08 \pm 0.05$. Mutants were clustered according to $\mathrm{pH}_{\mathrm{c}}$ with respect to growth rate (Materials and methods) and grouped according to functionally related gene ontology (GO) processes.

control of organellar $\mathrm{pH}$. Also, the same functions are not responsible for $\mathrm{pH}_{\mathrm{c}}$ control in different conditions. This shows that $\mathrm{pH}_{\mathrm{c}}$ is a seemingly simple outcome of diverse and intricate regulation. This renders $\mathrm{pH}_{\mathrm{c}}$ an excellent signal of cellular status.

\section{$\mathrm{pH}_{\mathrm{c}}$ as a signal integrating multiple environmental cues to control growth}

In yeast it has long been known that $\mathrm{pH}_{\mathrm{c}}$ transiently responds to the addition of nutrients $[18,23]$. The transient $\mathrm{pH}_{\mathrm{c}}$ reduction upon glucose addition plays a role in the activation of the nutrient signaling, growth-promoting activation of protein kinase $\mathrm{A}$ [44]. How exactly $\mathrm{pH}_{\mathrm{c}}$ functions in the activation of protein kinase $\mathrm{A}$ is not yet fully understood, but it is clear that a lowered $\mathrm{pH}_{\mathrm{c}}$ promotes the activity of the adenylate cyclase Cyr1p through the activity of Ira2p and Ras $2 p$ [45], and possibly also the increase in the affinity of Cyr1p for ATP upon a decrease in $\mathrm{pH}_{\mathrm{c}}$ [46]. Additionally, the gradual decrease of $\mathrm{pH}_{\mathrm{c}}$ upon glucose depletion was shown to lead to inactivation of protein kinase A, through the disassembly of the vacuolar proton ATPases $[10,19]$. Decrease of $\mathrm{pH}_{\mathrm{c}}$ upon glucose depletion also affects other signal transduction pathways. The activation of inositol biosynthetic gene transcription upon inositol depletion is inhibited in the absence of a proper energy source, through direct control of the activity of the transcriptional inhibitor Opi1p. This inhibitor is recruited to phosphatidic acid in membranes upon inositol depletion, directly binding to the negatively charged phospholipid. Upon $\mathrm{pH}_{\mathrm{c}}$ decrease the phosphate headgroup of the phospholipid is protonated, and Opilp is released $[7,47]$. Therefore, as phosphates can be protonated at physiological $\mathrm{pH}_{\mathrm{c}}$ values, and this can affect interactions with proteins, it is very likely that other phosphate groups, such as those on proteins or those on small metabolites, may be protonated and this protonation could then affect recognition by enzymes or effector proteins.

We identified three different classes of $\mathrm{pH}_{\mathrm{c}}$ mutants with respect to their cell division rate. The three classes are suggestive of different modes of functional interference with the $\mathrm{pH}_{\mathrm{c}}$-growth rate interdependence (Figure 6). We reasoned that any integrated effect of increased protonation of many cellular compounds that would lead to reduced growth by reduced $\mathrm{pH}_{\mathrm{c}}$ could not possibly be relieved by deletions of single ORFs. The fact, therefore,

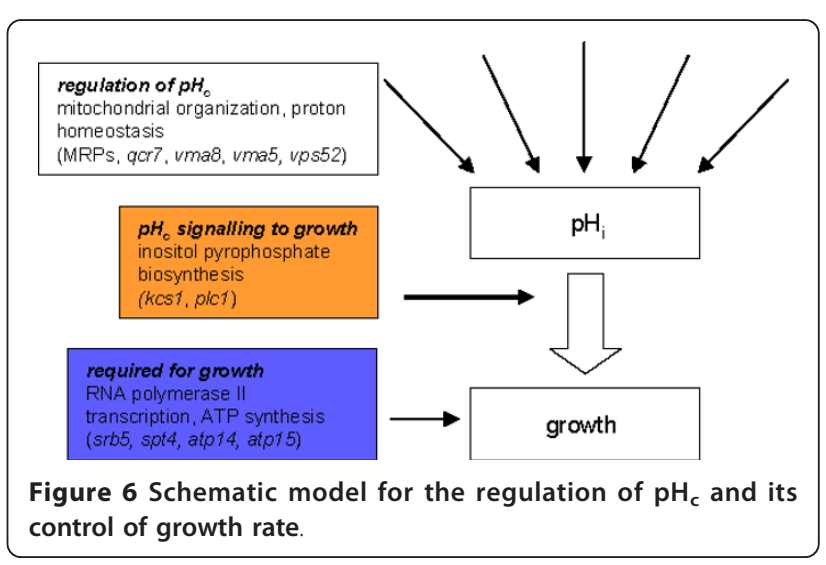


that strains mutated for a single gene have a higher than expected growth rate at a given $\mathrm{pH}_{\mathrm{c}}$ based on the wildtype $\mathrm{pH}_{\mathrm{c}}$-growth rate relationship suggests that $\mathrm{pH}_{\mathrm{c}}$ would function as a true second messenger $[7,10]$, providing a signal that is improperly transduced in only a very small number of deletion strains. This last observation reveals that the tight control of growth rate by $\mathrm{pH}_{\mathrm{c}}$ has evolved to become robust towards mutation, suggesting a high importance for cell or population fitness.

There is some evidence that $\mathrm{pH}_{\mathrm{c}}$ varies during the cell cycle $[48,49]$, but others have not been able to confirm this [50]. We show that $\mathrm{pH}_{\mathrm{c}}$ quantitatively controls cell division rate. This may or may not be through cell cycle phase-dependent fluctuations. However, the fact that the changes in $\mathrm{pH}_{\mathrm{c}}$ that we observed are in the range at which phosphate groups can be protonated, and the observation that such protonation can interfere with protein interactions [7], would allow many opportunities for $\mathrm{pH}_{\mathrm{c}}$ interference with cell cycle signaling.

Previously, is has been shown that the Vip1p pyrophosphorylation of InsP6 is important for phosphate regulation of growth [51,52]. Interestingly, they reveal an inhibitory interaction of inositol pyrophosphate with the alternative CDK Pho85p, suggesting that such interactions could control kinase function [39,52]. We now show that Kcs1p-mediated pyrophosphorylation of InsP6 is important for $\mathrm{pH}_{\mathrm{c}}$ signaling to set growth rate. It is tempting to speculate that these inositol pyrophosphate species appear to integrate signals from two major regulatory metabolites to determine growth rate. Indeed, a recent publication shows that inositol pyrophosphates contribute to cellular energy control [53], which is completely in line with the potential role of $\mathrm{pH}_{\mathrm{c}}$ in nutrient status sensing. The authors find that inositol pyrophosphates affect mitochondrial function and fermentation rates to control cellular ATP content. This suggests that $\mathrm{pH}_{\mathrm{c}}$, inositol pyrophosphates and mitochondria function in an interdependent network to control cell division, resource distribution, and therefore potentially the balance between growth and cellular robustness [53-57].

\section{The implications of $\mathrm{pH}_{\mathrm{c}}$ as a signal for growth and more}

In humans, $\mathrm{pH}_{\mathrm{c}}$ changes have been implicated in tumorigenic transformation and tumor growth and metastasis [58-60]. The reduction of oxygen availability in solid tumors causes a fermentative metabolism, described already in 1927 by Otto Warburg. This change leads to the production of lactate, which causes the acidification of the tumor exterior space and the surrounding tissue. Tumor cells themselves almost invariably overexpress $\mathrm{pH}$ homeostatic pumps $[61,62]$, leading to a selective advantage of transformed over non-transformed cells. Interestingly, our data suggest that the acidification of the non-transformed cells might result in a growth suppression, but also that the slightly alkaline tumor cell cytosol might have growth promoting activity. Indeed, it has been suggested that tumor alkalinization might already be a very early event in tumorigenic transformation [60], and an even slightly increased replication rate of the alkalinized cells could benefit the accumulation of mutations promoting the transformation to malignancy.

\section{Conclusions}

Intracellular $\mathrm{pH}$ is a determinant of the properties of the molecules that make up living cells, and changes in $\mathrm{pH}_{\mathrm{c}}$ rapidly and reversibly alter these properties. In yeast, $\mathrm{pH}_{\mathrm{c}}$ is highly dynamic. Although intracellular $\mathrm{pH}$ is hardly affected by changes in extracellular $\mathrm{pH}$, it is affected by the changes occurring during normal growth on glucose (Figure 1), and decreases as a consequence of $\mathrm{CO}_{2}$ produced by cellular metabolism. In respiratory conditions, either after glucose depletion or during growth on glycerol- and ethanol-containing media, $\mathrm{pH}$ is much lower than during fermentation.

To understand the genetic basis of $\mathrm{pH}_{\mathrm{c}}$ control during growth on glucose, we expressed the $\mathrm{pH}$-sensitive GFP pHluorin in all strains of the yeast haploid deletion collection. We analyzed $\mathrm{pH}_{\mathrm{c}}$ in liquid cultures of these strains during the exponential growth phase, and identified 177 mutants in which $\mathrm{pH}_{\mathrm{c}}$ deviated significantly from wild type. The genes affecting $\mathrm{pH}_{\mathrm{c}}$ control were strongly enriched for functions in the vacuole, including vacuolar proton pumping, but also for many mitochondrial functions, both in proton pumping and energy generation as well as in mitochondrial translation, biogenesis and inheritance. The fact that the same mutations did not lead to $\mathrm{pH}_{\mathrm{c}}$ alterations in respiratory conditions indicates that $\mathrm{pH}_{\mathrm{c}}$ control is condition dependent.

The most striking functional enrichment of the mutants was in very general growth-related functions. This could imply that $\mathrm{pH}_{\mathrm{c}}$ is reduced as a consequence of reduction in growth rate or as a consequence of the metabolic conditions that lead to a reduced growth rate, but it also opens up the possibility that growth rate is reduced as a consequence of the reduction in $\mathrm{pH}_{\mathrm{c}}$. We note that while conditions that decrease growth rate also generally reduce $\mathrm{pH}_{\mathrm{c}}$, mutations that reduce growth rate do not necessarily reduce $\mathrm{pH}_{\mathrm{c}}$. Also, $\mathrm{pH}_{\mathrm{c}}$ responds much more rapidly to external conditions than growth rate does. This suggests that either environmental conditions affect $\mathrm{pH}_{\mathrm{c}}$ and metabolism that sets growth rate in parallel, or that $\mathrm{pH}_{\mathrm{c}}$ in fact controls growth rate. To distinguish between these two options, we titrated $\mathrm{pH}_{\mathrm{ex}}$ with strong acid in cultures of the plasma membrane ATPase hypomorph pma1-007 that were otherwise unaffected in nutrient availability, and thereby reduced $\mathrm{pH}_{\mathrm{c}}$. This indeed led to a reduction of growth rate, quantitatively matching the relationship between $\mathrm{pH}_{\mathrm{c}}$ and growth rate observed in wild type. This 
proves that $\mathrm{pH}_{\mathrm{c}}$ directly controls growth rate. A further analysis of the genetic basis of this control shows that it was relaxed in only 19 out of 177 mutants. The fact that $\mathrm{pH}_{\mathrm{c}}$ control can be relaxed demonstrates that $\mathrm{pH}_{\mathrm{c}}$ must function as a signal, whereas the fact that this signal is not properly sensed in only 19 mutants suggests that it has evolved to be robust to mutation, and therefore that it is central and important.

Indeed, there is evidence that similar control takes place in mammalian cells. Although a link between $\mathrm{pH}$ control and tumorigenesis has been established, most research in this field focuses on the acidified cell exterior, which appears to affect metastatic propensity [59]. Very little is known about the role of the alkalinization of the cell interior. However, recent literature also suggests that, in mammalian cells too, $\mathrm{pH}_{\mathrm{c}}$ affects signal transduction $[8,9]$ and cell division rate [63-65]. The fact that we now show that cytosolic $\mathrm{pH}$ controls growth rate, and functions as a signal to do so, suggests that the relevance of $\mathrm{pH}_{\mathrm{c}}$ for growth control is conserved. How exactly this quantitative signal is controlled, and how it is transmitted to control the cell cycle, remains to be elucidated, but the involvement of the inositol pyrophosphate kinase Kcs1p, and of Plc1p gives promising targets for investigation.

\section{Materials and methods Growth conditions}

In all experiments strains were pre-cultured by transfer from solid medium to liquid and incubated overnight $(\mathrm{o} / \mathrm{n})$ in round-bottom 96-well microplates (Greiner BioOne, Kremsmünster, Austria)) stacked in microplate holders (New Brunswick, Enfield, CT, USA) under constant shaking at $30^{\circ} \mathrm{C}$ in $200 \mu$ low fluorescence synthetic defined monosodium glutamate medium buffered at $\mathrm{pH}$ 5.0 with $25 \mathrm{mM}$ sodium citrate. This medium contained 1.7 g yeast nitrogen base without (w/o) ammonium sulfate, w/o folic acid, w/o riboflavin (MP Biochemicals, Santa Ana, CA, USA), $1 \mathrm{~g}$ L-glutamic acid sodium salt hydrate (Sigma-Aldrich, St. Louis, MO, USA), 2 g drop-out amino acids supplement powder mixture without uracil (SigmaAldrich; Acros Organics, Geel, Belgium; Thermo Fisher Scientific, Waltham, MA, USA), 20 g glucose (Thermo Fisher Scientific) and 7.35 g sodium citrate (SigmaAldrich) per liter. For $\mathrm{pH}$ titration experiments, strains were cultivated in $500 \mathrm{ml}$ batch fermenters with a steady airflow (500 ml minute $\left.{ }^{-1}\right)$ and stirring rate (600 r.p.m.). The $\mathrm{pH}$ of batch fermenter cultures was controlled by titration with $0.2 \mathrm{M} \mathrm{KOH}$ using an Applikon ADI 1030 controller (Applikon Biotechnology, Foster City, CA, USA).

\section{Strain construction}

The plasmid pYES-P $\mathrm{P}_{\mathrm{ACT1}}$-pHluorin [18] was introduced into the MAT $\alpha$ query strain Y7092 and crossed with the
MATa DMA using SGA technology [26], yielding a complete set of mutants expressing pHluorin in the cytosol. Mutants that displayed a slow growing phenotype were set up in a separate array, allowing for longer incubation times on the different SGA media.

\section{Metabolite analysis}

Ethanol, acetate, succinate and pyruvate concentrations in the medium were determined by high pressure liquid chromatography. To this extent, $1.0 \mathrm{ml}$ of sample was quenched with $100 \mu \mathrm{l}$ of $35 \%$ perchloric acid followed by a neutralization with $55 \mu \mathrm{l}$ of $7 \mathrm{M} \mathrm{KOH}$. Samples were analyzed on a Phenomenex Rezex ROA-Organic Acid $\mathrm{H}^{+}$column (Phenomenex, Utrecht, The Netherlands) using $7.2 \mathrm{mM} \mathrm{H}_{2} \mathrm{SO}_{4}$ as mobile phase.

\section{Screening for mutants with deviating $\mathrm{pH}_{\mathrm{c}}$}

Unless stated otherwise, strains were pre-cultured $\mathrm{o} / \mathrm{n}$ in microplates, diluted 10-fold into fresh medium in CELLSTAR black polystyrene clear-bottom 96-well microplates (Greiner Bio-One) and grown for 4 hours to ensure exponential growth. Plates were transferred to the Automated Cell, Compound and Environment Screening System (ACCESS) [66] and incubated at $30^{\circ} \mathrm{C}$ under constant shaking until automatically transferred to a Safire ${ }^{2}$ microplate reader (Tecan, Männedorf, Switzerland). Optical density at $600 \mathrm{~nm}\left(\mathrm{OD}_{600}\right)$ was measured followed by two fluorescence measurements at $390 \mathrm{~nm}$ and $470 \mathrm{~nm}$ excitation, both with $512 \mathrm{~nm}$ emission. After background subtraction the ratio of the two fluorescence measurements was compared to a calibration curve to determine $\mathrm{pH}_{\mathrm{c}}$ as described in [18]. The array was screened twice and the 2,136 wild-type measurements were used to determine an average wild-type $\mathrm{pH}_{\mathrm{c}}$ with according standard deviation. For every mutant in the array the average $\mathrm{pH}$ was converted to a $\mathrm{Z}$-value defined as the number of standard deviations their measured $\mathrm{pH}$ was removed from the average wildtype $\mathrm{pH}_{\mathrm{c}}$ in that replicate. Mutants with a $\mathrm{Z}$-value at least higher than 2 or lower than -2 once and higher than 1 or lower than -1 in the other screening were selected as 'candidate hits' and combined with the slow grower array for additional confirmatory screening. Candidate hits and slow grower arrays were precultured as described and subjected to six rescreening runs where $\mathrm{OD}_{600}$ was measured with a SpectraMax Plus384 microplate spectrophotometer (Molecular Devices, Sunnyvale, CA, USA) followed by pHluorin fluorescence measurements using a SpectraMax Gemini XS microtitre plate spectrofluorometer (Molecular Devices). In each of these replicates, mutant $\mathrm{pH}_{\mathrm{c}}$ values were converted to $\mathrm{Z}$-values with respect to average and standard deviation of the wild-type population in that replicate. Significant scores were determined based on a two-tailed $t$-test of 
these rescreening $\mathrm{Z}$-values compared to the wild-type data $(P<0.01)$. For the analysis of the candidate hits based on the initial two genome-wide screens, for rigidity we did not include the $\mathrm{pH}_{\mathrm{c}}$ values used for identification in the determination of significance. Doing so would have improved $P$-values for all $\mathrm{pH}_{\mathrm{c}}$ mutants identified. For the slow growing mutants, to avoid bias originating from outliers, we performed a second analysis discarding the lowest and highest replicate value for each mutant (Jackknife), and retesting significance. Mutants with $P$-values $>0.1$ in this analysis were discarded as significant. Both average Z-values and average $\mathrm{pH}_{\mathrm{c}}$ values are presented. All mutants identified as significant were subjected to microscopical analysis: strains were grown in microplates for at least 2 hours as described above. After washing with phosphate-buffered saline, cells were transferred to agarose-coated glass slides. Images were obtained using a Canon A620 camera (Canon, Tokyo, Japan) on an Axiovert 40 CFL microscope with a Plan Neofluar 100 X/NA 1.3 oil objective (Carl Zeiss, Oberkochen, Germany), using Endow GFP narrow-band excitation filter sets (Chroma Technology, Bellows Falls, VT, USA) for fluorescent images.

\section{Profiling of mutants with aberrant $\mathrm{pH}_{\mathrm{c}}$ under additional stress conditions}

After $\mathrm{o} / \mathrm{n}$ inoculation in described conditions, cells were transferred to fresh medium buffered at $\mathrm{pH} 3.0$ with 25 $\mathrm{mM}$ potassium citrate (Sigma-Aldrich), pH 7.5 with 25 mM MOPS (Sigma-Aldrich) or 2\% ethanol and 2\% glycerol as the carbon source. These experiments were conducted at least three times. Deviation was determined using $t$-tests comparing to the parent strain.

\section{Hypergeometric distribution analysis}

Enrichment of data sets for gene ontology terms was performed using the Yeast GO-term finder [67].

\section{Growth curve analysis}

After $\mathrm{o} / \mathrm{n}$ inoculation hits identified in the initial screen were re-inoculated and subsequently monitored for 16 hours by $\mathrm{OD}_{600}$ and $\mathrm{pH}_{\mathrm{c}}$ measurements every 10 minutes in a FLUOstar OPTIMA microplate reader (BMG labtech, Ortenberg, Germany). Growth data were corrected for the non-linearity of optical recording at higher cell densities similar to the method in [68], correcting $\mathrm{OD}_{600}$ values recorded in the microplate reader $\left(\mathrm{OD}_{\mathrm{obs}}\right)$ to reflect linear $\mathrm{OD}_{600}$ determinations of the same cultures in a Novaspec II spectrophotometer (Pharmacia LKB Biochrom, Cambridge, UK) (always diluting the cultures to yield measured values between 0.05 and $0.3 \mathrm{OD}$ units) using the formula $\mathrm{OD}_{\text {cor }}=$ $1.1252\left(\mathrm{OD}_{\mathrm{obs}}\right)^{2}+0.6808\left(\mathrm{OD}_{\mathrm{obs}}\right)-0.0002$. Growth rates of cultures in time were determined by calculating the slope of six consecutive data points (1 hour) of the entire $\ln \left(\mathrm{OD}_{\text {cor }}\right)$ curve.

\section{Cluster analysis}

For cluster analysis 190 independent 12-hour $\mathrm{pH}_{\mathrm{c}}$ growth curves of the wild-type strain were used to fit the variables in:

$$
\mu=10 \frac{p H_{c}+a}{b}
$$

where $a$ was determined be to $-7.24 \pm 0.06$, and $b$ to $0.73 \pm 0.08$. We used this fit to predict the growth rate at each time point based on the $\mathrm{pH}_{\mathrm{c}}$ measured at that time, for all wild-type and mutant strain time courses. We next determined the biological variance at each time point of the measured $\mu$ values around the predicted $\mu$ values of the 190 individual wild-type replicates, resulting in a mean and standard deviation of the wild-type divergence from the prediction at each time point. Using this mean and standard deviation, we transformed individual wild-type and mutant curves to $\mathrm{Z}$-values at all time points. $t$-Test analyses of the average mutant $\mathrm{Z}$ values compared to all wild-type replicates for all time points between $\mathrm{t}=4 \mathrm{~h}$ to $\mathrm{t}=9 \mathrm{~h}$ was multiplied by a correction factor to eliminate false positives based on $P$ values of wild-type time courses in a same $t$-test. Zvalues of mutant and wild-type $\mu / \mathrm{pH}_{\mathrm{c}}$ curves, from $\mathrm{t}=4$ $\mathrm{h}$ to $\mathrm{t}=9 \mathrm{~h}$, were hierarchically clustered using Euclidean distances with full linkage.

\section{Additional material}

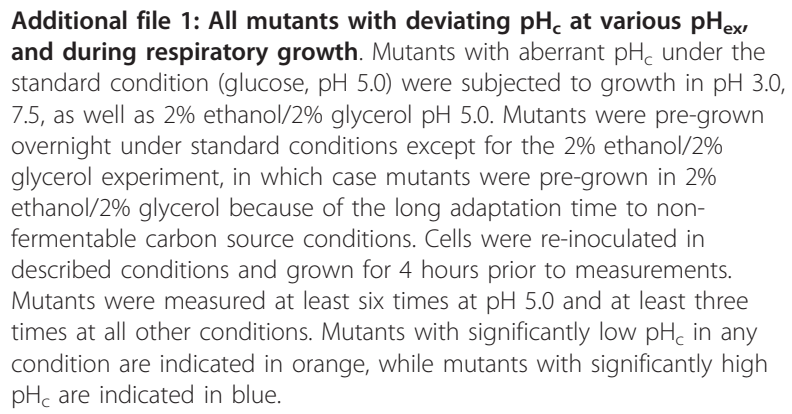

Additional file 2: $\mathbf{p H}_{\mathrm{c}}$ analysis of $\mathbf{4 3 2}$ slow growing mutants. All strains were grown in standard conditions ( $2 \%$ glucose, $\mathrm{pH}_{\mathrm{ex}}$ of 5.0$)$ and fluorescence was registered in three to six biological replicates, and are presented as average and 95\% confidence interval. $\mathrm{pH}_{\mathrm{c}}$ was compared to wild-type (WT) controls in the same replicate, to determine a Z-value. Significance of the $\mathrm{pH}_{\mathrm{c}}$ difference with WT was determined using a twotailed $t$-test assuming equal variance with a $P$-value $<0.05$. ND refers to mutants for which fewer than three replicates were successfully measured. Significantly low $\mathrm{pH}_{\mathrm{c}}$ values are shown in orange, significantly high $\mathrm{pH}_{\mathrm{c}}$ values in blue.

Additional file 3: Classification of mutants. Mutants are classified as having a growth rate- $\mathrm{pH}_{\mathrm{c}}$ relationship similar to wild type (WT; no significant deviation from the predicted growth rate based on $\mathrm{pH}_{\mathrm{c}^{-}}$ 
growth rate relationship of the parent strain, low growth rate/ $\mathrm{pH}_{c}$ (significant positive deviation from the parent fit), or high growth rate/ $\mathrm{pH}_{\mathrm{c}}$ (significant negative deviation from the parent fit), and are categorized according to functional classification.

Additional file 4: Figures S1 to S4. See Additional file 5 for further data pertaining to Figure $\mathrm{S} 3$.

Additional file 5: Data belonging to the hierarchical cluster plot in Figure S3 in Additional file 4. Mutants are listed in the order in which they appear in the cluster plot, for all three clusters. Mutant growth profiles were fitted to the parent strain $\mathrm{pH}_{c}$-growth rate relationship, and at each time point the Z-value of the digression from the fit was determined compared to the average and variance of 96 parent strain growth curves at the same time point. Time courses during the growth phase ( $\mathrm{t}=4 \mathrm{~h}$ to $\mathrm{t}=9 \mathrm{~h}$ ) of these Z-values were used to statistically categorize the mutants as wild type (WT; 92/173 mutants; 96 parent strain profiles also fall in this category), significantly (corrected $P$-value < $0.01)$ slow growing (62/173 mutants), or significantly fast growing (19/173 mutants) with respect to $\mathrm{pH}_{\mathrm{c}}$.

\section{Abbreviations}

DMA: deletion mutant array; GFP: green fluorescent protein; InsP6: inositol hexakisphosphate; OD: optical density; ORF: open reading frame; $\mathrm{pH}_{c}$ : cytosolic $\mathrm{pH}$; $\mathrm{pH}_{\mathrm{ex}}$ : external $\mathrm{pH}$; SGA: synthetic genetic array.

\section{Acknowledgements}

We thank Azmat Ullah, Wing Kit Man, Nydia van Dyk and Lawrence Heisler for assistance with experiments. This work was partially funded by Unilever (RO and GJS). Work in CN and GG's laboratory is supported by the NHGRI and CIHR (MOP-81340 and MOP-84305) and the Canadian Cancer Society (020380); work in CB and FV's laboratory was supported by the CIHR (MOP97939)

\section{Author details}

${ }^{1}$ Molecular Biology and Microbial Food Safety, Swammerdam Institute for Life Sciences, University of Amsterdam, Science Park 904, 1098 XH Amsterdam, the Netherlands. ${ }^{2}$ Banting and Best Department of Medical Research, Terrence Donnelly Centre for Cellular and Biomolecular Research, University of Toronto, Toronto, Ontario M5S 3E1, Canada. ${ }^{3}$ Department of Molecular Genetics, Terrence Donnelly Centre for Cellular and Biomolecular Research, University of Toronto, Toronto, Ontario M5S 3E1, Canada.

\section{Authors' contributions}

$\mathrm{RO}$ designed and performed most of the experiments and their analysis, and participated in drafting the manuscript. MLU set up the genome-wide screening. FJV performed the SGA recombination experiments. GG, CB, CN and SB assisted in experimental design, analysis, and drafting of the article. GJS conceived of the study, participated in its design and coordination, performed most data analysis and drafted the manuscript. All authors read and approved the final manuscript.

\section{Competing interests}

The authors declare that they have no competing interests.

Received: 30 March 2012 Revised: 10 September 2012

Accepted: 26 September 2012 Published: 26 September 2012

\section{References}

1. Veine $D M$, Arscott LD, Williams CH Jr: Redox potentials for yeast, Escherichia coli and human glutathione reductase relative to the NAD +/NADH redox couple: enzyme forms active in catalysis. Biochemistry 1998, 37:15575-15582.

2. Roos A, Boron WF: Intracellular pH. Physiol Rev 1981, 61:296-434.

3. Goffeau A, Amory A, Villalobo A, Dufour JP: The H+-ATPase of the yeast plasma membrane. Ann N Y Acad Sci 1982, 402:91-98.

4. Whitten ST, Garcia-Moreno EB, Hilser VJ: Local conformational fluctuations can modulate the coupling between proton binding and global structural transitions in proteins. Proc Natl Acad Sci USA 2005, 102:4282-4287.

5. Kooijman EE, Tieleman DP, Testerink C, Munnik T, Rijkers DT, Burger KN, de Kruijff B: An electrostatic/hydrogen bond switch as the basis for the specific interaction of phosphatidic acid with proteins. J Biol Chem 2007, 282:11356-11364.

6. Casey JR, Grinstein S, Orlowski J: Sensors and regulators of intracellular pH. Nat Rev Mol Cell Biol 2010, 11:50-61.

7. Young BP, Shin JJ, Orij R, Chao JT, Li SC, Guan XL, Khong A, Jan E, Wenk MR, Prinz WA, Smits GJ, Loewen CJ: Phosphatidic acid is a pH biosensor that links membrane biogenesis to metabolism. Science 2010, 329:1085-1088.

8. Simons M, Gault WJ, Gotthardt D, Rohatgi R, Klein TJ, Shao Y, Lee HJ, Wu AL, Fang Y, Satlin LM, Dow JT, Chen J, Zheng J, Boutros M, Mlodzik M: Electrochemical cues regulate assembly of the Frizzled/Dishevelled complex at the plasma membrane during planar epithelial polarization. Nat Cell Biol 2009, 11:286-294.

9. Cruciat CM, Ohkawara B, Acebron SP, Karaulanov E, Reinhard C, Ingelfinger $D$, Boutros $M$, Niehrs $C$ : Requirement of prorenin receptor and vacuolar $\mathrm{H}+$-ATPase-mediated acidification for $\mathrm{Wnt}$ signaling. Science 2010, 327:459-463.

10. Dechant R, Binda M, Lee SS, Pelet S, Winderickx J, Peter M: Cytosolic pH is a second messenger for glucose and regulates the PKA pathway through V-ATPase. EMBO J 2010, 29:2515-2526.

11. Vojinovic $V$, von Stockar $\mathrm{U}$ : Influence of uncertainties in $\mathrm{pH}, \mathrm{pMg}$, activity coefficients, metabolite concentrations, and other factors on the analysis of the thermodynamic feasibility of metabolic pathways. Biotechnol Bioeng 2009, 103:780-795.

12. Orij R, Brul S, Smits GJ: Intracellular pH is a tightly controlled signal in yeast. Biochim Biophys Acta 2011, 1810:933-944.

13. Arino J, Ramos J, Sychrova H: Alkali metal cation transport and homeostasis in yeasts. Microbiol Mol Biol Rev 2010, 74:95-120.

14. Brett $C L$, Tukaye DN, Mukherjee $S$, Rao R: The yeast endosomal $\mathrm{Na}+\mathrm{K}+/ \mathrm{H}+$ exchanger $\mathrm{Nhx} 1$ regulates cellular $\mathrm{pH}$ to control vesicle trafficking. $\mathrm{Mol}$ Biol Cell 2005, 16:1396-1405.

15. Lasorsa FM, Scarcia P, Erdmann R, Palmieri F, Rottensteiner H, Palmieri L. The yeast peroxisomal adenine nucleotide transporter: characterization of two transport modes and involvement in DeltapH formation across peroxisomal membranes. Biochem J 2004, 381:581-585.

16. Martinez-Munoz GA, Kane P: Vacuolar and plasma membrane proton pumps collaborate to achieve cytosolic $\mathrm{pH}$ homeostasis in yeast. J Biol Chem 2008, 283:20309-20319.

17. Miesenbock G, De Angelis DA, Rothman JE: Visualizing secretion and synaptic transmission with $\mathrm{pH}$-sensitive green fluorescent proteins. Nature 1998, 394:192-195.

18. Orij R, Postmus J, Ter Beek A, Brul S, Smits GJ: In vivo measurement of cytosolic and mitochondrial $\mathrm{pH}$ using a $\mathrm{pH}$-sensitive GFP derivative in Saccharomyces cerevisiae reveals a relation between intracellular $\mathrm{pH}$ and growth. Microbiology 2009, 155:268-278.

19. Tarsio M, Zheng H, Smardon AM, Martinez-Munoz GA, Kane PM: Consequences of loss of Vph1 protein-containing vacuolar ATPases (V-ATPases) for overall cellular pH homeostasis. J Bio/ Chem 2011, 286:28089-28096.

20. Giaever G, Chu AM, Ni L, Connelly C, Riles L, Véronneau S, Dow S, LucauDanila A, Anderson K, André B, Arkin AP, Astromoff A, El-Bakkoury M, Bangham R, Benito R, Brachat S, Campanaro S, Curtiss M, Davis K, Deutschbauer A, Entian KD, Flaherty P, Foury F, Garfinkel DJ, Gerstein M, Gotte D, Güldener U, Hegemann JH, Hempel S, Herman Z, et al: Functional profiling of the Saccharomyces cerevisiae genome. Nature 2002, 418:387-391.

21. den Hollander JA, Ugurbil K, Brown TR, Shulman RG: Phosphorus-31 nuclear magnetic resonance studies of the effect of oxygen upon glycolysis in yeast. Biochemistry 1981, 20:5871-5880.

22. Kresnowati MT, Suarez-Mendez CM, van Winden WA, van Gulik WM, Heijnen JJ: Quantitative physiological study of the fast dynamics in the intracellular $\mathrm{pH}$ of Saccharomyces cerevisiae in response to glucose and ethanol pulses. Metab Eng 2008, 10:39-54.

23. Thevelein JM, Beullens M, Honshoven F, Hoebeeck G, Detremerie K, Griewel B, den Hollander JA, Jans AW: Regulation of the CAMP level in the yeast Saccharomyces cerevisiae: the glucose-induced cAMP signal is not mediated by a transient drop in the intracellular $\mathrm{pH}$. J Gen Microbiol 1987, 133:2197-2205. 
24. Goossens A, de La Fuente N, Forment J, Serrano R, Portillo F: Regulation of yeast $\mathrm{H}(+)$-ATPase by protein kinases belonging to a family dedicated to activation of plasma membrane transporters. Mol Cell Biol 2000, 20:7654-7661.

25. Serrano R: In vivo glucose activation of the yeast plasma membrane ATPase. FEBS Lett 1983, 156:11-14.

26. Tong AH, Boone $\mathrm{C}$ : Synthetic genetic array analysis in Saccharomyces cerevisiae. Methods Mol Biol 2006, 313:171-192.

27. Carmelo V, Bogaerts P, Sa-Correia I: Activity of plasma membrane $\mathrm{H}$ +-ATPase and expression of PMA1 and PMA2 genes in Saccharomyces cerevisiae cells grown at optimal and low pH. Arch Microbiol 1996, 166:315-320

28. Merz S, Westermann B: Genome-wide deletion mutant analysis reveals genes required for respiratory growth, mitochondrial genome maintenance and mitochondrial protein synthesis in Saccharomyces cerevisiae. Genome Biol 2009, 10:R95.

29. Dimmer KS, Fritz S, Fuchs F, Messerschmitt M, Weinbach N, Neupert W, Westermann B: Genetic basis of mitochondrial function and morphology in Saccharomyces cerevisiae. Mol Biol Cell 2002, 13:847-853.

30. Hess DC, Myers CL, Huttenhower C, Hibbs MA, Hayes AP, Paw J, Clore JJ, Mendoza RM, Luis BS, Nislow C, Giaever G, Costanzo M, Troyanskaya OG, Caudy AA: Computationally driven, quantitative experiments discover genes required for mitochondrial biogenesis. PLoS Genet 2009, 5: e1000407.

31. Eide DJ, Clark S, Nair TM, Gehl M, Gribskov M, Guerinot ML, Harper JF: Characterization of the yeast ionome: a genome-wide analysis of nutrient mineral and trace element homeostasis in Saccharomyces cerevisiae. Genome Biol 2005, 6:R77.

32. Jiang D, Zhao L, Clapham DE: Genome-wide RNAi screen identifies Letm1 as a mitochondrial $\mathrm{Ca2}+/ \mathrm{H}+$ antiporter. Science 2009, 326:144-147.

33. Carmelo V, Santos H, Sa-Correia I: Effect of extracellular acidification on the activity of plasma membrane ATPase and on the cytosolic and vacuolar pH of Saccharomyces cerevisiae. Biochim Biophys Acta 1997, 1325:63-70.

34. Porat Z, Wender $\mathrm{N}$, Erez $\mathrm{O}$, Kahana C: Mechanism of polyamine tolerance in yeast: novel regulators and insights. Cell Mol Life Sci 2005, 62:3106-3116.

35. Gaudreau L, Schmid A, Blaschke D, Ptashne M, Horz W: RNA polymerase II holoenzyme recruitment is sufficient to remodel chromatin at the yeast PHO5 promoter. Cell 1997, 89:55-62.

36. Steinmetz EJ, Warren CL, Kuehner JN, Panbehi B, Ansari AZ, Brow DA: Genome-wide distribution of yeast RNA polymerase II and its control by Sen1 helicase. Mol Cell 2006, 24:735-746.

37. Lin H, Fridy PC, Ribeiro AA, Choi JH, Barma DK, Vogel G, Falck JR, Shears SB, York JD, Mayr GW: Structural analysis and detection of biological inositol pyrophosphates reveal that the family of VIP/diphosphoinositol pentakisphosphate kinases are 1/3-kinases. J Biol Chem 2009, 284:1863-1872.

38. Auesukaree C, Tochio H, Shirakawa M, Kaneko Y, Harashima S: PIc1p, Arg82p, and Kcs1p, enzymes involved in inositol pyrophosphate synthesis, are essential for phosphate regulation and polyphosphate accumulation in Saccharomyces cerevisiae. J Biol Chem 2005, 280:25127-25133.

39. Lee YS, Mulugu S, York JD, O'Shea EK: Regulation of a cyclin-CDK-CDK inhibitor complex by inositol pyrophosphates. Science 2007, 316:109-112.

40. Serrano R, Bernal D, Simon E, Arino J: Copper and iron are the limiting factors for growth of the yeast Saccharomyces cerevisiae in an alkaline environment. J Biol Chem 2004, 279:19698-19704.

41. Sambade M, Alba M, Smardon AM, West RW, Kane PM: A genomic screen for yeast vacuolar membrane ATPase mutants. Genetics 2005, 170:1539-1551.

42. Brett CL, Kallay L, Hua Z, Green R, Chyou A, Zhang Y, Graham TR, Donowitz M, Rao R: Genome-wide analysis reveals the vacuolar pH-stat of Saccharomyces cerevisiae. PLoS One 2011, 6:e17619.

43. Johnson D, Nehrke K: Mitochondrial fragmentation leads to intracellular acidification in Caenorhabditis elegans and mammalian cells. Mol Biol Cell 2010, 21:2191-2201.

44. Thevelein JM: Fermentable sugars and intracellular acidification as specific activators of the RAS-adenylate cyclase signalling pathway in yeast: the relationship to nutrient-induced cell cycle control. $\mathrm{Mol}$ Microbiol 1991, 5:1301-1307.
45. Colombo S, Ma P, Cauwenberg L, Winderickx J, Crauwels M, Teunissen A, Nauwelaers D, de Winde JH, Gorwa MF, Colavizza D, Thevelein JM: Involvement of distinct G-proteins, Gpa2 and Ras, in glucose- and intracellular acidification-induced CAMP signalling in the yeast Saccharomyces cerevisiae. EMBO J 1998, 17:3326-3341.

46. Purwin C, Nicolay K, Scheffers WA, Holzer H: Mechanism of control of adenylate cyclase activity in yeast by fermentable sugars and carbonyl cyanide m-chlorophenylhydrazone. J Biol Chem 1986, 261:8744-8749.

47. Shin JJ, Loewen CJ: Putting the $\mathrm{pH}$ into phosphatidic acid signaling. BMC Biol 2011, 9:85.

48. Anand S, Prasad R: Rise in intracellular pH is concurrent with 'start' progression of Saccharomyces cerevisiae. J Gen Microbiol 1989, 135:2173-2179.

49. Gillies RJ, Ugurbil K, den Hollander JA, Shulman RG: 31P NMR studies of intracellular $\mathrm{pH}$ and phosphate metabolism during cell division cycle of Saccharomyces cerevisiae. Proc Natl Acad Sci USA 1981, 78:2125-2129.

50. Karagiannis J, Young PG: Intracellular pH homeostasis during cell-cycle progression and growth state transition in Schizosaccharomyces pombe. J Cell Sci 2001, 114:2929-2941.

51. Mulugu S, Bai W, Fridy PC, Bastidas RJ, Otto JC, Dollins DE, Haystead TA, Ribeiro AA, York JD: A conserved family of enzymes that phosphorylate inositol hexakisphosphate. Science 2007, 316:106-109.

52. Lee YS, Huang K, Quiocho FA, O'Shea EK: Molecular basis of cyclin-CDKCKI regulation by reversible binding of an inositol pyrophosphate. Nat Chem Biol 2008, 4:25-32.

53. Szijgyarto Z, Garedew A, Azevedo C, Saiardi A: Influence of inositol pyrophosphates on cellular energy dynamics. Science 2011, 334:802-805.

54. Zakrzewska A, van Eikenhorst G, Burggraaff JE, Vis DJ, Hoefsloot $H$, Delneri D, Oliver SG, Brul S, Smits GJ: Genome-wide analysis of yeast stress survival and tolerance acquisition to analyze the central trade-off between growth rate and cellular robustness. Mol Biol Cell 2011, 22:4435-4446

55. Rodriguez-Colman MJ, Reverter-Branchat G, Sorolla MA, Tamarit J, Ros J, Cabiscol E: The forkhead transcription factor $\mathrm{Hcm} 1$ promotes mitochondrial biogenesis and stress resistance in yeast. J Biol Chem 2010, 285:37092-37101.

56. Pastor MM, Proft M, Pascual-Ahuir A: Mitochondrial function is an inducible determinant of osmotic stress adaptation in yeast. J Biol Chem 2009, 284:30307-30317

57. Dagley MJ, Gentle IE, Beilharz TH, Pettolino FA, Djordjevic JT, Lo TL, Uwamahoro N, Rupasinghe T, Tull DL, McConville M, Beaurepaire C, Nantel A, Lithgow T, Mitchell AP, Traven A: Cell wall integrity is linked to mitochondria and phospholipid homeostasis in Candida albicans through the activity of the post-transcriptional regulator Ccr4-Pop2. Mol Microbiol 2011, 79:968-989.

58. Cardone RA, Casavola V, Reshkin SJ: The role of disturbed pH dynamics and the $\mathrm{Na}+\mathrm{H}+$ exchanger in metastasis. Nat Rev Cancer 2005, 5:786-795.

59. Webb BA, Chimenti M, Jacobson MP, Barber DL: Dysregulated pH: a perfect storm for cancer progression. Nat Rev Cancer 2011, 11:671-677.

60. Reshkin SJ, Bellizzi A, Caldeira S, Albarani V, Malanchi I, Poignee M, AlunniFabbroni M, Casavola V, Tommasino M: $\mathrm{Na}+/ \mathrm{H}+$ exchanger-dependent intracellular alkalinization is an early event in malignant transformation and plays an essential role in the development of subsequent transformation-associated phenotypes. FASEB J 2000, 14:2185-2197.

61. De Milito A, Fais S: Tumor acidity, chemoresistance and proton pump inhibitors. Future Oncol 2005, 1:779-786.

62. Rofstad EK, Mathiesen B, Kindem K, Galappathi K: Acidic extracellular pH promotes experimental metastasis of human melanoma cells in athymic nude mice. Cancer Res 2006, 66:6699-6707.

63. Putney LK, Barber DL: Na-H exchange-dependent increase in intracellular pH times G2/M entry and transition. J Biol Chem 2003, 278:44645-44649.

64. Harada K, Oita E, Chiba K: Metaphase I arrest of starfish oocytes induced via the MAP kinase pathway is released by an increase of intracellular pH. Development 2003, 130:4581-4586.

65. Sellier C, Bodart JF, Flament S, Baert F, Gannon J, Vilain JP: Intracellular acidification delays hormonal G2/M transition and inhibits G2/M transition triggered by thiophosphorylated MAPK in Xenopus oocytes. J Cell Biochem 2006, 98:287-300.

66. ACCESS, an Automated Cell, Compound and Environment Screening System.. [http://med.stanford.edu/sgtc/technology/access.html]. 
67. Generic Gene Ontology Term Finder. [http://go.princeton.edu/cgi-bin/ GOTermFinder].

68. Warringer J, Blomberg A: Automated screening in environmental arrays allows analysis of quantitative phenotypic profiles in Saccharomyces cerevisiae. Yeast 2003, 20:53-67.

doi:10.1186/gb-2012-13-9-r80

Cite this article as: Orij et al: Genome-wide analysis of intracellular pH reveals quantitative control of cell division rate by $\mathrm{pH}_{c}$

in Saccharomyces cerevisiae. Genome Biology 2012 13:R80.

Submit your next manuscript to BioMed Central and take full advantage of:

- Convenient online submission

- Thorough peer review

- No space constraints or color figure charges

- Immediate publication on acceptance

- Inclusion in PubMed, CAS, Scopus and Google Scholar

- Research which is freely available for redistribution

Submit your manuscript at www.biomedcentral.com/submit 